\title{
Advanced use of the urban metabolism model in rapidly changing cities
}

\author{
R. Roggema ${ }^{1,2}$ \& A. A. Alshboul ${ }^{3}$ \\ ${ }^{1}$ Van Hall Larenstein University of Applied Sciences, The Netherlands \\ ${ }^{2}$ National Institute for Design Research, Swinburne University of \\ Technology, Australia \\ ${ }^{3}$ Department of Architecture, The University of Jordan, Jordan
}

\begin{abstract}
For the calculation of energy and other flows in urban environments, we should take as a starting point relatively stable urban settlements. This makes it possible to calculate in and outgoing flows accurately, but only at a single moment in time. In this paper an adjusted approach to urban metabolism is proposed in which dynamic circumstances can be incorporated, suitable for urban settlements under pressure of rapid and unprecedented change. As examples we take the nearly uncontrollable growth of Almafraq in Jordan as a result of Syrian refugees and the changes in the population of Vlagtwedde in the Netherlands under influence from natural shrinkage and influx of (temporary) asylum seekers. The core questions answered here are: the way to calculate energy flows as input for sustainable urban design when population change is serious and the way to design cities when incorporating the results of dynamic urban metabolism. The research is ongoing and promises innovative results in the near future.

Keywords: dynamic metabolism, energy storage, renewable energy, urban metabolism, rapid change, urban design, refugees.
\end{abstract}

\section{Introduction}

In this paper we would like to address a necessary innovation in thinking about energy supply. The movement from an energy supply completely based on fossil resources towards renewables is only one side of the coin. On the other side the use and re-use of scarce resources receive increasing attention. The so-called metabolism of the city aims to reduce the use of energy (input) and limits its effluent (output). However, even if the rest-heat is recycled and re-used in the 
same city, this model aims to calculate for a certain moment in time, or a for an accurately predictable future. Sudden changes, caused by climate impacts or demographic fluctuations, are not included. These sudden changes require a wider metabolism model, and are considered as a subsystem of a more comprehensive city metabolism model characterized by flexibility.

In this article we start with a description of the metabolism model, followed by the circular metabolism model. We then define our proposition of a dynamic metabolism model and its potential spatial impacts, before we discuss rough metabolism calculations for Almafraq and Vlagtwedde under influence of sudden significant changes. We end with conclusions and a pledge for a new design research agenda.

The first introduction of the metabolism (of cities) concept described, main metabolic problems of water supply, disposal of sewage and air pollution [1]. In past periods, thinking in metabolic cycles of input and output 'transactions' were new. Principally, the model describes the city as an ecosystem with inputs of energy and materials and managing the increasing outputs. A definition of urban metabolism is: 'the sum of the technical and socio-economic processes that occur in cities, resulting in growth, production of energy, and elimination of waste' [2]. In current times, it is clear that when the majority of the global population lives in cities [3], cities must be recognised as the most important place to address environmental threats, such as climate change, water stress, loss of biodiversity and resource scarcity [4-7]. The urban metabolism model, integrating engineered infrastructures, people and natural systems are important in understanding and increasing sustainability of cities [3].

This model allows us to analyze, quantify and follow functionalities of the city, such as an increased efficiency of resource use, the recycling of waste and the conservation and production of energy [8] (figure 1). The 'Extended Metabolism Model of a City' defines the goal of sustainability as the minimization of natural resources depletion and production of waste while simultaneously improving its liveability so that it can better fit within the capacities of local regional and global ecosystems [8]: the best way to reduce the impact of the city is to reduce the input of resources (e.g. resource management). This framework for urban metabolism includes inflows, outflows, internal flows, storage and production of biomass, minerals, water, and energy, allows for peri-urban activities such as production of food or forestry [9].

Moreover, each resource has its specific scope. Some, such as material flows can be directed through input management, while others, such as fossil fuels, require a trans-boundary understanding, as storage within the city is insignificant. Water combines storage within the city with trans-boundary flows [10]. The emphasis put on cross-scale interactions between the natural system, trans-boundary engineered infrastructures and multiple social actors [11], explains the complexity of interconnecting city elements and functions, but even these approaches lack the role of reuse and recycling in a circular manner, substitution of resources by sustainable variants and the consequences and opportunities to reach sustainability through spatial design. Illustrative is that in three major lit reviews from respectable institutions [12-14] 
the scope is limited to in- and output flows, sometimes extended to social aspects, such as liveability or governance, but aspects of recycling (limited to the urban system per se [14]), spatial aspects (only found in [14]) and the type of resource are mostly conspicuous by their absence. Additionally, calculations are often averages, which do not take into account frequencies, higher amplitudes and changes occurring on short timeframes (days/seasons).

Currently, many cities use a large amount of resources, which, after being processed lead to relatively low environmental quality and liveability, high amount of waste and emissions. The fundamental criticism is that although the current discourse on urban metabolism is inspiring thinking about the sustainability of the city [15], emphasising reduced input and waste flows and improving liveability and environmental quality (figure 2), it only takes into account recycling and the use of sustainable resources or spatial design to a very limited extent.
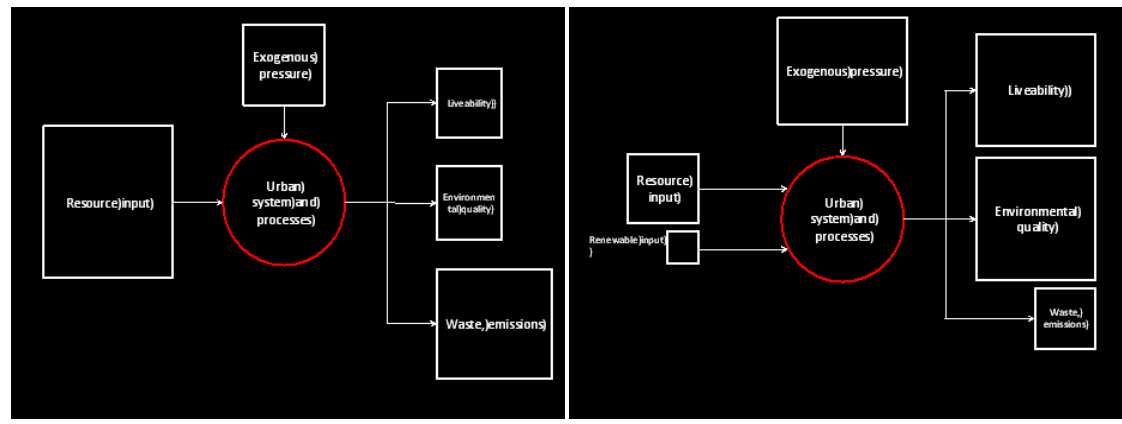

Figure 1: Current situation, after Newman [8] and the metabolism model with reduced in- and output flows.

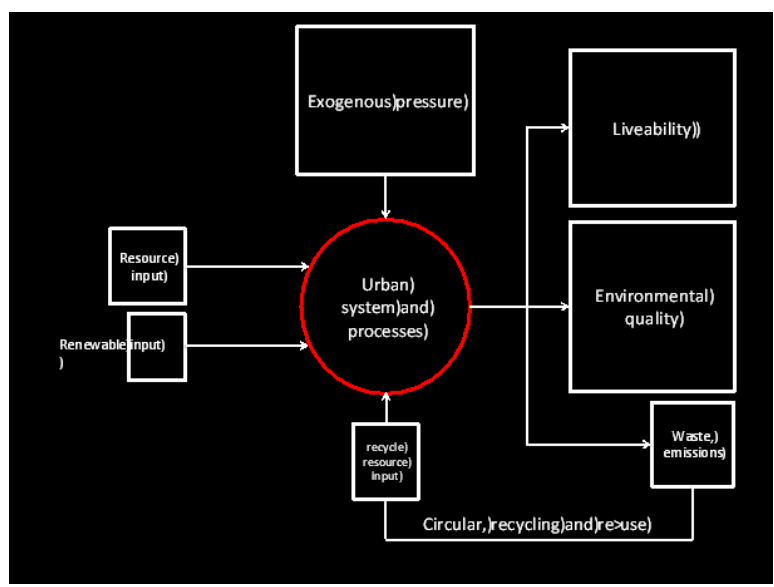

Figure 2: $\quad$ Circular metabolism. 
Sustainable urban futures require a fundamental transformation of existing production and consumption patterns. The natural world is taken as a template for architecture and urban development [15]. Seldom, a metabolic approach is taken as basis for an urban design that envisioned cities and buildings as going through the same process of change, renewal, and destruction as other natural life cycle forms [16]. Cities could be designed to change over time and be flexible enough to maintain a constant cycle of growth, transformation, and death of its parts without destruction of the whole [17].

\section{Circular and dynamic metabolism impacts on spatial planning}

Linear metabolism [18], with inputs and outputs is problematic and is contrasted with a cyclic approach being efficient in the use of materials and energy [19]. Circular metabolism is defined as "where every output can be used as an input for another process [20]. Long term sustainability of cities is then seen as being reliant on shifting from the linear to a circular model of metabolism, in which outputs are recycled back into the system to become inputs [21] providing both cost savings as environmental benefits [19], such as applied in Hammarby Sjöstad [22], building a city along the cradle-to-cradle principles, closed metabolic systems that produce no waste [23]. Material loops refer to the circulation of materials in contemporary manufacturing processes viewed as systems. Resource inputs (steel, petroleum, cement, sewage) are treated equally as waste outputs (slag, plastic, sulphuric gas, sludge). Regionally scalable, the decentralisation of urban waste streams creates circular economies creating lines of production and landscapes of disassembly [24]. Instead of civil engineering forming their own profession separated from the landscape profession, waste recycling makes infrastructure (including management of water, waste, food, transport and energy) extreme relevant for landscape planning and design, because the structures of urban rural economies change and decentralise. Food production and energy networks can no longer be engineered without considering the cascade of waste streams and cycling of raw materials input [25]. The engineering of basic elements, such as topography, hydrology and biomass as a system can be instrumental in the amplification of invisible yet fundamental processes that support urban development. As a dualised practice, design can be strategically deployed between two different scales: short, immediate periods of time with large geographic effects, over long periods of time [25]. Design, and the research that preconditions it, therefore becomes telescopic [26], capable of integrating multiple scales of intervention at once.

Design of surface systems, synchronisation of material volumes, logistics of implementation re-zoning of land across boundaries, sequencing of land transformations over time, synergies between land uses, and reciprocities between different agencies, can therefore augment and accelerate these strategies, placing emphasis on performative aspects of practice rather than their end results. The new paradigms of longevity and performance decisively break 
with the Old World pictorial, bucolic and aesthetic tradition of landscape design. Instead they give landscape design a logistical and operative agency as a practice dealing with complex multi-dimensional systems [25].

Circular economies emphasises the latent reciprocity between industry, waste and urbanism. It requires multilateral strategies, including waste diversion, separation, recycling, composting and remanufacturing, effective as durable alternatives to conventional systems of waste management, that previously relied on consolidated forms of disposal. These emerging infrastructures are networked, flexible and recursive [24].

Developing 'Circular Urban Systems' [27] implies creating connections between previously separate systems, i.e. systems integration. While the objective of circular urban metabolism seems to be to close cycles of material and energy, it also requires change in technologies, organisations and institutions of multiple systems [28]. Approaching metabolism as a circular system, its efficient processing leads to lower waste flows, better environmental quality and liveability, and recycling and reuse function as additional input in the system. Still, this represents an inappropriate understanding of ecosystems [29], because from a complex systems point of view the focus of urban metabolism on circularity, balance and order is challenged. Instead, these systems are in continual interaction with each other and the outside world [30, 31], leading to the idea that ecological design for urban areas should not aim for stability and predictability, but a greater resilience to inevitable internal and external shocks that will impact the urban area [15] must be achieved. Taking natural systems as a model, self-sufficiency is regarded as one of the most important characteristics of sustainable metabolism, reducing dependence from a wider hinterland for resources extraction or waste disposal [32-34]. The city and urban environment must therefore be seen as a complete system of planning, designing and managing urban areas [35], for which the spatial characteristics that influence material and energy flows then logically must be understood and a long term analysis is required [36]. Here, we could learn from nature and apply four basic ecological principles [37]: interdependence, cyclical flow of resources, cooperation and partnership. These principles determine how an ecosystem organises itself, optimises sustainability, and is able to sustain its 'web of life' [38], and can be used as basis for developing cities [20]. Therefore, current differences between natural systems and cities (table 1) need to be overcome.

Table 1: Natural and city systems compared [20].

\begin{tabular}{|c|c|}
\hline Natural system & City \\
\hline No waste & Constant production of waste \\
\hline $\begin{array}{l}\text { Network of chemical reactions are the basis of } \\
\text { functions and behaviour of organisms }\end{array}$ & $\begin{array}{l}\text { Networks of infrastructure are the basis of city } \\
\text { form, which dictates behaviour, resource usage } \\
\text { and social interaction }\end{array}$ \\
\hline $\begin{array}{l}\text { Organisms maintain themselves, adapt and } \\
\text { regenerate without centralised control }\end{array}$ & $\begin{array}{l}\text { Networks rely on control and are organised as } \\
\text { hierarchal diagrams }\end{array}$ \\
\hline $\begin{array}{l}\text { Ecological model is supported by a large } \\
\text { number of producer flows }\end{array}$ & $\begin{array}{l}\text { City model is an inverted pyramid, with a low } \\
\text { number of producers supplying a large number } \\
\text { of consumers }\end{array}$ \\
\hline
\end{tabular}


Where living networks constantly correct themselves, urban form has no such ability. Would it be possible to design our cities in a way where constant selforganisation improves the ability to correct itself? In order to allow for this it is necessary to increase the diversity in the city. The more diverse the more resilient a city will become. Lending from ecology, the biodiversity is a result of the complexity of networks, more complex networks imply more complex patterns of interaction [20].

Our main concern is that, even circular, metabolism does not include design/spatial impacts and the peaks and lows of required resources over short or sudden timeframes. Especially when the population shrinks or increases the metabolism model does not automatically and under all circumstances serve the sustainability of these communities. Therefore, we propose to put emphasis on the time dimensions of population change and to accommodate the impacts supply of renewable resources, the production of stock and the re-use of flows locally in spatial design propositions. Therefore the dynamism of quick changing patterns in resource in- and output, including internal storage and production of supply needs to become a part of the metabolism model (figure 3), as well as increasing the diversity in the city that processes the in- and outflows.

As population can shrink and grow over time, the metabolism model, or better the in- and outflow of resources, need to be capable of adjusting as well. When the amount of people is shrinking less resources are required. We estimate that most of these can be supplied from recycled waste or renewable resources and use of traditional resources is minimal. At other times, when population increases, more resources are needed. The main part can be provided using recycled or re-used waste and renewable resources. Especially the fraction of recycled waste needs to increase in order to meet the demands of the growing amount of people, because a sudden growth in renewable resources is impossible. To start producing the supply when the population suddenly increases may prove to be too late. In other words, these resources need already be present and become available when demand grows. This implies that these resources need to be kept in storage until the moment they are required. In the design for cities space must be created for these storages. In the dynamic
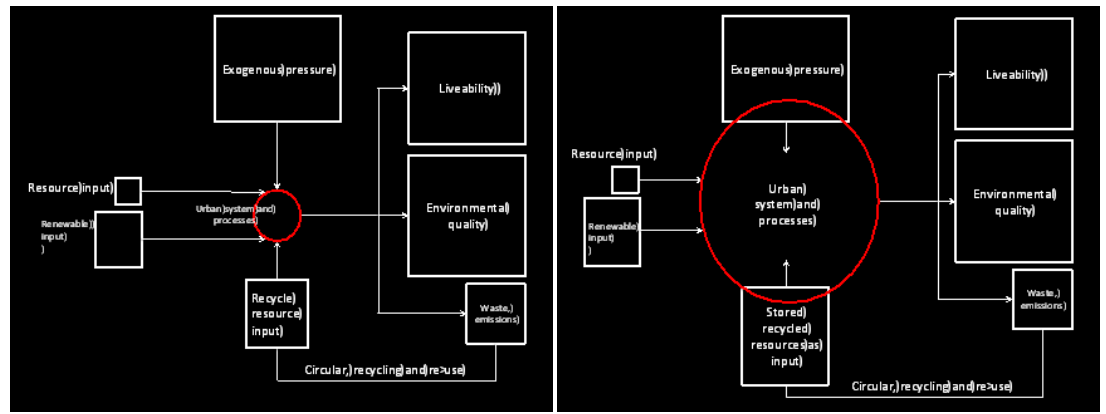

Figure 3: $\quad$ The metabolism model in changing circumstances. 
metabolism of the city, spatial provisions need to be created for storage as well as for the production of renewable resources, such as food, energy and water.

The consequences of thinking in circular urban metabolism are (partly) spatial. Reversely, it is possible to define optimised urban patterns and city design that provide the best conditions for sustainability. Remarkably, density doesn't explain the environmental friendliness of cities [39], but several other spatial qualifications do:

○ There needs to be space in the city to produce and harvest renewable resources, such as wind, solar, geothermal, hydropower and biomass. Which combination of energy potentials is suitable differs per region. It is recommended to use the method of Energy Potential Mapping [40] to identify how these potentials are spatially spread.

- Earlier research has highlighted the need to create space for temporary land-use as result of the uncertainty around future climate impacts. Around $30 \%$ of the land-use needs to be able to transform its functions whenever necessary, while current planning allows only $2 \%$ [41]. This space can be used by all kinds of functions (e.g. agriculture, nature, sport-fields, parking space), as long as it is possible to change functions instantly, for instance when space is required to mitigate a flood, bushfire or other impact. Meantime these spaces can play a role in providing renewable energy, harvest food or clean and store water.

- Space needs to be made available to store energy (batteries, water-towers, fall lakes, flywheels, etcetera) and other resources (again: water and food). The stored resources need to become available when the demand, for instance as a result of, sudden, population growth, increases.

○ In the urban network the diversity in functions, shapes, sizes and appearances needs to be enhanced in order to increase the complexity and by doing so, the resilience of the city.

These spatial factors are usually not a very significant part of urban development. Even stronger, when unexpected or unprecedented change occurs, the urban system is often disrupted and faces difficulties adjusting. In our proposition these factors are important elements of the urban design for cities that can be confronted with sudden change.

\section{Case studies: Almafraq and Vlagtwedde}

Our theoretical framework forms the basis for ongoing research in two case studies: Almafraq in Jordan and Vlagtwedde in the Netherlands. At this stage the research hasn't been finished, which allows for describing the system, defining strategic responses and for suggesting energetic solutions.

The city of Almafraq is located in northern Jordan. The climate is semi hot arid, the soil is sandy with low ability to hold humidity for longer periods. High solar radiation intensity is a major characteristic of the district. It is located close to the Syrian border. The Syrian crisis and the flow of refugees created a sudden pressure upon the infrastructure of Almafraq with 120,000 refugees arriving in two years. This creates a great pressure upon the local environment and 
ecosystems. In order to understand the dynamics of energy and material flows a metabolism model to be developed helps to establish strategies to deal with sudden large amounts of refugees. These people need to be provided with a place to live, e.g. they need water, food, shelter and energy. However, it is unpredictable how many people will come and what the expected demand in energy will be. The current population of Almafraq district is 281,100 [42], which each use, in 2012, an average of $1,736 \mathrm{MWh} / \mathrm{pp} / \mathrm{py}$ [43], a total of $99,156.8 \mathrm{GWh} / \mathrm{py} .2 \%$ of this energy is renewable and the rest comes from fossil resources [44]. Current energy input is mainly kerosene $\left(E_{k}\right), L P G\left(E_{L P G}\right)$, fossil based electricity $\left(E_{e}\right)$ and solar energy $\left(E_{\text {solar }}\right)$ as well as food $(F)$. Common building types are residential, and little public and office buildings do exist. Energy flows follow the growth of the system, assuming no unexpected exogenous factors occur that may create pressure upon energy infrastructure of the district. Assuming the district as an open, stable system receiving energy and materials, producing $\mathrm{CO}_{\mathrm{x}}, \mathrm{NO}_{\mathrm{x}}$, and solid waste (SW), the system works with full capacity for the current population (P) but when population increases with $50 \%$ a deficit of system inputs becomes a serious problem and an uncertain amount of energy needs to be supplied additionally. An estimated maximum amount, projected for 2030 is supplied in a subsequent way by saving $20 \%$ energy, which is the average estimate in the European Union [45], 20\% produced using renewable resources, which is an extrapolated estimate from the $10 \%$ reached in 2015 [44], and an estimated 30\% coming from recycled and stored waste flows. This leads to a remaining demand, supplied by fossil resources, of $30 \%$. This maximum scenario determines the maximum Giga Watts that can be saved, reused and produced with renewable resources. This makes it possible to calculate the remaining need for fossil resources in case the total population grows less.

Once the amount of renewable generated energy is known, these can be designed, first as a system design and subsequently as a spatial urban design in which spaces for storage and renewables determine the complexity and diversity of the urban system and its patterns. In the case of Almafraq the typology of storage and renewables predominantly consists of PV- and wind farms, largesize batteries and distributed fuel cisterns and tanks. Figure 4 shows the system's dynamics, reducing pressure due to population increases.

The municipality of Vlagtwedde is located in the northeast of the Netherlands, close to the German border. In one of its towns a facility for asylum seekers, who are to be relocated in their home country is present. Due to uncertain amount of asylum seekers reaching this stage in their procedures, the total population in Vlagtwedde is uncertain. The current (1 August 2103) population is 15,964 [46], which, in 2012, used an average of $6,750 \mathrm{MWh} / \mathrm{pp} / \mathrm{py}$ [43], a total of $107,757 \mathrm{GWh} / \mathrm{yr}$. In $201195.7 \%$ of this amount was supplied with fossil resources [47]. The population of Vlagtwedde is predicted to shrink to 15,043 in 2013 [48]. However, this decrease is more than compensated by an estimated growth of the asylum seeker facility with 2000 persons $[49,50]$ and the possibility of a sudden rise in population with 200 persons due to a temporary campsite created by asylum seekers, which has 
occurred in May 2012 [51]. The total maximum population in 2013 can therefore be estimated at 17,243 using a total amount of $116,390 \mathrm{GWh} / \mathrm{yr}$. This total energy use is supplied through an energy efficiency of 20\% [45] increase of the portion of renewable resources to $40 \%$ [52] and an estimated $30 \%$ recycled and stored energy from rest or surplus production. The remaining $10 \%$ of energy needs to be provided from fossil resources. If we take these numbers as the maximum amount of energy produced through saving, renewables and storage, the amount of required fossil resources can be calculated in every population scenario. A 'shrunken' population with zero asylum seekers requires no fossil resources anymore. Once the amount of renewable energy and storage facilities are known, these can be designed. Again, the system design determines the urban design in which storage and renewables harvest determines the complexity and diversity of the urban system and its patterns. In the case of Vlagtwedde the typology of storage and renewables predominantly consists of biomass, solar and wind energy, and storage lakes and water towers.

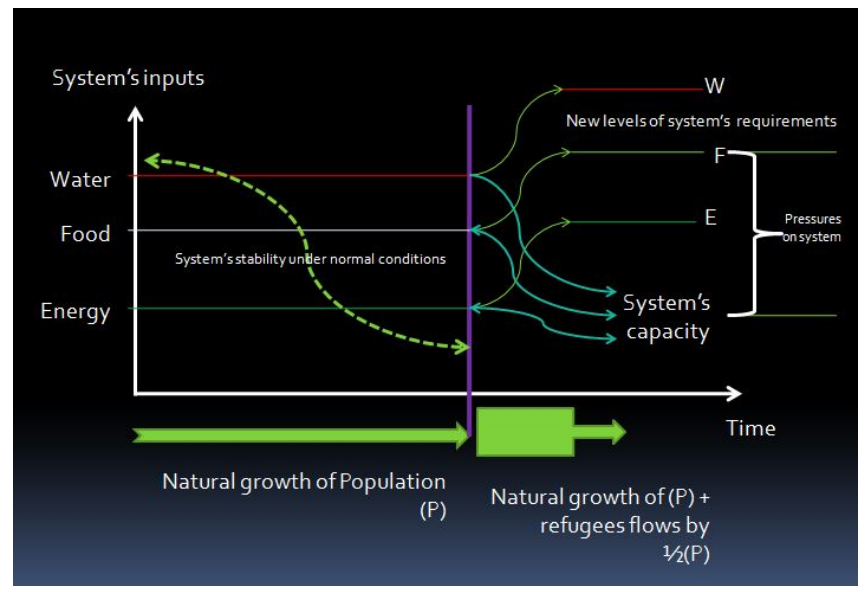

Figure 4: System dynamics under rapid changing population in Almafraq city.

\section{Results and recommendations}

The findings in our research to date suggest urban metabolism model for highly dynamic environments must be adjusted and include urban flows more dynamically. Secondly, the strategic response to these dynamics is to increase energy storage capacity and the supply with renewable energy also. This increased flexibility in addition to the supply must be sufficient to meet demands even in the most demanding situation. The third finding is the type of solutions proposed in each of the case studies: storage and renewables that are typically for the climate and landscape. 
These preliminary findings leave us with several recommendations. First the urban metabolism must be developed as a dynamic model, which is adjustable during times of change. Secondly, the urban design of energy measures that increase the flexibility of supply could solve demand fluctuations and must be further elaborated. Thirdly, the calculations and modelling of highly dynamic environments as input in the metabolism model must be further expanded. In this respect, finalising the current research will provide additional findings in the near future.

\section{Conclusions and discussion}

In this article the preliminary results were presented of on-going research. We cannot present final results yet, but only our proposed innovations in current thinking about urban metabolism, develop strategic responses and suggest solutions that need to be tested through future modelling. Nevertheless, this study leads to the following insights:

1. Current metabolism modelling only very limited includes recycling of waste-flows and storage of energy, the use of sustainable resources or spatial implementation of these flows and resources in the design.

2. Dynamic change in the demand, such as sudden needs for energy is not included in the calculations, as these are often conducted for an average number of citizens, regardless of a decrease in population. This should be adjusted in a way that systems will be based on a potential demand, determined by the highest estimated needs.

3. In our research dynamic metabolism the exemplary function is energy, but besides energy water, food and other provisions must also be included in the modelling as the demand for these resources also fluctuates in dynamic environments. Only a combination of dynamic flows is capable of forming a circular city concept.

4. Following pour research, we propose a design research agenda, focusing on the question where in the city spaces for storage and harvesting of renewable energy resources can be planned and created, how these can be designed and what effective design interventions are to provide responses to sudden demands and requirements.

\section{References}

[1] Wolman, A. (1965) The Metabolism of Cities. Scientific American Inc. 213 (3) $179-190$

[2] Kennedy, C.A., J. Cuddihy and J. Engel-Yan (2007) The changing metabolism of cities. Journal of Industrial Ecology 11 (2) 43-59

[3] Kennedy, C., L. Baker, S. Dhakal and A. Ramaswami (2012) Sustainable Urban Systems, An Integrated Approach. Journal of Industrial Ecology 16 (6) $775-779$ 
[4] Grimm, N., S.H. Faeth, N. Golubiewski, C. Redman, J. Wu, X. Bai and J. Briggs (2008) Global change and the ecology of cities. Science 319 $756-760$

[5] UNEP (2012) Sustainable Resource efficient cities - Making it happen! Paris: UNEP Division of Technology, Industry and Economics

[6] UN-HABITAT (2011) Cities and climate change: Global report on human settlements. Nairobi: UN-HABITAT

[7] World Bank (2010) Cities and climate change: An urgent agenda. Washington DC: World Bank

[8] Newman, P.W.G. (1999) Sustainability and cities: extending the metabolism model. Landscape and Urban Planning 44 (4) 219-226

[9] Kennedy, C. and D. Hoornweg (2012) Mainstreaming Urban Metabolosim.Journal of Industrial Ecology 16 (6) 780-782

[10] Ramaswami, A., A. Chavez and M. Chertow (2012) Carbon Footprinting of Cities and Implications for Analysis of Urban Material and Energy Flows. Journal of Industrial Ecology 16 (6) 783-785

[11] Ramaswami, A., C. Weible, D. Main, T. Heikkila, S. Siddiki, A. Duvall, A. Pattison and M. Bernard (2012) A Social-Ecological-Infrastructural Systems Framework of Sustainable City Systems. Journal of Industrial Ecology 16 (6) 801-813

[12] Holmes, T. and S. Pincetl (2012) Urban Metabolism Literature Review. Los Angeles: Center for Sustainable Urban Systems, UCLA Institute of the Environment

[13] Rapoport, E. (2011) Interdisciplinary Perspectives on Urban Metabolism: A review on the literature. London: UCL Development Planning Unit, UCL Environment Institute

[14] Minx, J., F. Creutzig, V. Medinger, T. Ziegler, A. Owen and G. Baiocchi (2010) Developing a Pragmatic Approach to Assess Urban Metabolism in Europe. A report to the European Environment Agency. Stockholm: SEI and Technische Universität Berlin

[15] CastánBroto, V., A. Allen and E. Rapoport (2012) Interdisciplinary Perspectives on Urban Metabolism. Journal of Industrial Ecology 16 (6) 851-861

[16] Kurokawa, K. (1999) Kuala Lumpur International Airport. Stuttgart: Axel Menges

[17] Kurokawa, K. (1977) Metabolism in architecture. London: Studio Vista

[18] Girardet, H. (1992) The Gaia atlas of cities: New directions for sustainable urban living. London: Gaia Books

[19] Dunn, B.C. and A. Steinemann (1998) Industrial ecology for sustainable communities. Journal of Environmental Planning and Management 41 (6) 661-672

[20] Karakiewicz, J. (2011) Urban Metabolism of Low Carbon Cities.Proceedings $47^{\text {th }}$ ISOCARP Congress. Wuhan, China; 24-28 October 2011

[21] Girardet, H. (2008) Cities, people, planet: Urban development and climate change. Chichester: John Wiley 
[22] City of Stockholm (2007) HammarbySjöstad - A unique environmental project in Stockholm. Stockholm: City of Stockholm

[23] McDonough, W. and M. Braungart (2009) Cradle to Cradle: Remaking the way we make things. London: Vintage

[24] Bélanger, P. (2007) Landscapes of disassembly. Topos 60 83-91

[25] Bélanger, P. (2009) Landscape As Infrastructure. Landscape Journal 28 (1) 79-95

[26] Cosgrove, D. (2003) Apollo's Eye: A Cartographic Genealogy of the Earth in the Western Imagination. Baltimore: Johns Hopkins Press

[27] Vernay, A-L. (2013) Circular Urban Systems - Moving Towards Systems Integration. PhD-thesis. Delft: Delft University of Technology

[28] Vernay, A.L. and R. Singh (2012) Circular Urban Systems - Tracing innovation processes. Paper presented at the $2^{\text {nd }}$ World Sustainability Forum (online), November 2012

[29] Golubiewski, N. (2012) Is there a metabolism of an urban system? An ecological critique.Ambio 41 (7) 751-764

[30] Alberti, M. (1999) Modelling the urban ecosystem: A conceptual framework. Environment and Planning B 26 (4) 605-630

[31] Alberti, M. (2008) Advances in urban ecology: Integrating humans and ecological processes in urban ecosystems. New York: Springer

[32] Baccini, P. (1997) A city's metabolism: Towards the sustainable development of urban systems. Journal of Urban Technology 4 (2) 27-39

[33] Brunner, P.H. (2007) Reshaping urban metabolism. Journal of Industrial Ecology 11 (2) 11-13

[34] Niza, S., L.Rosado and P. Ferrão (2009) Urban metabolism: Methodological advances in urban material flow accounting based on the Lisbon case study. Journal of Industrial Ecology 13 (3) 384-405

[35] Suzuki, H., A. Dastur, S. Moffatt, N. Yabuki and H. Maruyama (2009) Eco2 Cities: Ecological cities as economic cities. Washington DC: World Bank

[36] Moffatt, S. and N. Kohler (2008) Concepualising the built environment as a social-ecological system. Building Research and Information 36 (3) 248268

[37] Capra, F. (1984) The Turning Point: Science, Complexity and the Rising Culture. New York: Batman Books

[38] Capra, F. (1997) The web of life: a new scientific understanding of living systems. New York: Anchor Books

[39] Newman, P. (2006) The environmental impact of cities. Environment and Urbanisation 18 (2) 275-295

[40] Van den Dobbelsteen, A., S. Jansen, A. van Timmeren and R. Roggema (2007) Energy Potential Mapping -A systematic approach to sustainable regional planning based on climate change, local potentials and exergy. Proceedings CIB World Congress, Cape Town, 14-18 May 2007

[41] Roggema, R. (2012) Swarm Planning: The development of a Methodology to Deal with Climate Adaptation. PhD-thesis. Delft, Wageningen: Delft 
University of Technology and Wageningen University and Research Centre.

[42] Jordan Department of Statistics (2010) Jordan in Figures

[43] http://www.indexmundi.com/map/?v=81000 Accessed: 17 November 2013

[44] Hartoqa, F. (2013) Jordan: Renewable Energy Market. US Commercial Service, United States of America, Department of Commerce http://export.gov/jordan/static/jordan\%20renewable\%20energy\%20market _latest_eg_jo_034925.doc Accessed: 18 November 2013

[45] EC (2013a) The EU climate and energy package. http://ec.europa.eu/clima/policies/package/index_en.htm Accessed: 18 November 2013

[46] CBS, http://nl.wikipedia.org/wiki/Vlagtwedde_(gemeente), Accessed: 24 December 2013

[47] CBS (2012) Renewable energy in the Netherlands 2011. Den Haag/Heerlen: Statistics Netherlands

[48] Gemeente Bellingwedde (2009) Hoofdlijnen Basisonderwijs Gemeente Bellingwedde. Visie op onderwijsbeleid van een bijzondere gemeente in een snel veranderende wereld 2010 - 2020. Interne notitie. URL: http://www.veelerveen.eu/content/images/stories/hoofdlijnen $\% 20$ basisond erwijs \%20gemeente $\% 20$ bellingwedde $\% 2030-3$ 2011\%20pdf\%20versie.pdf Accessed: 18 November 2013

[49] Staatscourant (2013) Vaststelling bestemmingsplan 'TerApelervenen', Vlagtwedde. Staatscourant, Jaargang 2013, nr. 22048. https//zoek.officielebekendmakingen.nl/stcrt-2013-22048 Accessed: 17 November 2013

[50] Gemeente Vlagtwedde (2013) Bijlagen bestemmingsplanTerApelervenen. Gemeente Vlagtwedde. https:/www.vlagtwedde.nl/RiSBisDocumenten/ Raadstukken/163/1667/14.07.\%20Vaststellen\%20bestemmingsplan\%20Te r\%20Apelervenen\%20\%20toelichting\%20bijlagen\%201.pdf Accessed: 17 November 2013

[51] Boonstra, W. (2012) Wie is erverantwoordelijk in situatie TerApel?

[52] Binnenlands Bestuur, 15 mei 2012 http://www.binnenlandsbestuur.nl/ bestuur-en-organisatie/nieuws/wie-is-verantwoordelijk-in-situatie-terapel.6085823.lynkx

[53] EC (2013b) Roadmap for moving to a low-carbon economy in 2050. http://ec.europa.eu/clima/policies/roadmap/index_en.htm Accessed: 18 November 2013 